\title{
УДК 621.315.592
}

DOI: https://doi.org/10.36910/6775-2313-5352-2019-14-8

Галян ${ }^{1}$ В.В., Іващенко ${ }^{2}$ І.А, Олексеюк ${ }^{2}$ І.Д., Федосов ${ }^{1}$ С.А., Третяк ${ }^{1}$ А.П., Данилюк ${ }^{3}$ І.В., Лебедь ${ }^{4}$ О.О., Кевшин ${ }^{1}$ А.Г., Тищенко ${ }^{2}$ П.В.

${ }^{1}$ Кафедра експериментальної фізики та інформаційно-вимірювальних технологій, Східноєвропейський національний університет імені ЛесіУкраїнки, Україна;

${ }^{2}$ Кафедра неорганічної та фізичної хімії, Східноєвропейський національний університет імені ЛесіУкраїнки, Україна;

${ }^{3}$ Кафедра екології та охорони навколишнього середовища, Східноєвропейський національний університет імені Лесі Українки, Україна

${ }^{4}$ Кафедра хімії та фізики, Національний університет водного господарства та природокористування

\section{МЕХАНІЗМ ФОТОЛЮМІНЕСЦЕНЦІї МОНОКРИСТАЛУ $\left(\mathrm{Ga}_{54.59} \mathbf{I n}_{44.66} \mathbf{E r}_{0.75}\right)_{2} \mathbf{S}_{300}$}

Монокристал ( $\left.G a_{54.59} I_{44.66} E r_{0.75}\right)_{2} S_{300}$ вирощений методом розчину-розплаву і опромінений $\gamma$-променями дозою 420, 1260, 2520, 5040 Гр з допомогою джерела ${ }^{60}$ Со. Зафіксовано інтенсивне люмінесиентне випромінювання в інтервалах $1,48-1,61$ i 0,75-0,86 еВ при збудженні лазером із довжиною хвилі 532 нм. Побудовано діаграму енергетичних рівнів для іонів Ербію та встановлено механізм випромінювання, в якому важливу роль відіграє прочес кросрелаксачії. При високих дозах опромінення (2520, 5040 Гр) відбувається збільшення інтенсивності люмінесиентного випромінювання, яке пов'язується із ростом концентрації $\gamma$ індукованих дефектів кристалу.

Ключові слова: фотолюмінесценція, кросрелаксація, спектр поглинання.

\section{Вступ}

Отримання нових матеріалів і дослідження їх властивостей $є$ одним із основних напрямків сучасного матеріалознавства. Введення до бінарних, тернарних сполук [1-3] легуючих домішок, зокрема рідкісноземельних металів [4-6], створює передумови для виготовлення активних і пасивних середовищ в лазерній техніці та телекомунікаціях. Крім того, особливу увагу науковці приділяють властивостям кристалічних та аморфних середовищ, які здатні стабільно проявляти фотолюмінесценцію (ФЛ) високої інтенсивності та нелінійнооптичні властивості під впливом радіації $[7,8]$. Оптичні методи реєстрації $\gamma$-опромінення $\epsilon$ перспективними завдяки високій чутливості, селективності і можливістю використання в різних середовищах. Люмінесцентне випромінювання найбільше чутливе до $\gamma$-променів, внаслідок їх високої проникної здатності. Крім того, створення радіаційно-стійких матеріалів $\epsilon$ одним із основних завдань радіаційної фізики та хімії твердого тіла для використання в космічних технологіях оптоелектронної техніки.

Для дослідження сцинтиляційних матеріалів, в якості активаторів легуючої домішки, часто слугують рідкісноземельні метали $\mathrm{Ce}, \mathrm{Nd}, \mathrm{Pr}, \mathrm{Eu}[9,10,11]$.

Крім того, аналізують $\gamma$-опромінені кристали і стекла, леговані Ербієм, їх застосовують в якості середовищ в оптоволоконних мережах, оптичних підсилювачах та телекомунікація, тому мотивами дослідження є радіаційна стійкість, та вплив $\gamma$-опромінення на втрати оптичного сигналу $[12,13]$. Необхідно відзначити, що деякі кристали і стекла, леговані Er вивчають, як сцинтилятори радіаційного опромінення $[14,15]$.

В наших попередніх дослідженнях [16] в системі $\mathrm{Ga}_{2} \mathrm{~S}_{3}-\operatorname{In}_{2} \mathrm{~S}_{3}$ зафіксовані дві потрійні сполуки: $\mathrm{GaInS}_{3}$ та $\mathrm{Ga}_{0.7} \mathrm{In}_{1.3} \mathrm{~S}_{3}$. Сполука $\mathrm{GaInS}_{3}$ утворюється по перитектичній реакції $\mathrm{L}+\mathrm{In}_{2} \mathrm{~S}_{3}$ $\leftrightarrow \mathrm{GaInS}_{3}$ при $1190 \mathrm{~K}$, кристалізується в гексагональній сингонії, пр. гр. $P 6_{1}, a=0.6655(4)$ нм, $c$ $=1.7950(3) \mathrm{Hм}$, володіє областю гомогенності, яка при 820 К складає 47-57 мол.\% $\operatorname{In}_{2} \mathrm{~S}_{3}$.

Крім того, X-променевою фотоелектронною спектроскопією ми дослідили внутрішні оболонки і валентну зону для вихідного і бомбардованого іонами Ar поверхні монокристалу $\left(\mathrm{Ga}_{54.59} \mathrm{In}_{44.66} \mathrm{Er}_{0.75}\right)_{2} \mathrm{~S}_{300}$ [17]. Виявлено, що цей монокристал був радіаційно стійкий по відношенню до Ar-іонного бомбардування. Зокрема, така обробка не викликає яких-небудь істотних змін значень енергій зв'язку електронів із внутрішніх оболонок, а також форми рентгенівських фотоелектронних спектрів (XPS) на рівні внутрішніх оболонок і валентної зони монокристалу. В роботі [17] вважається, що введення Ербію в решітку $\left(\mathrm{Ga}_{55} \operatorname{In}_{45}\right)_{2} \mathrm{~S}_{300}$ не приводить до значних змін в особливостях хімічного зв'язку вихідного (нелегованого Ербієм) монокристалу.

(C) Галян ${ }^{1}$ В.В., Іващенко ${ }^{2}$ I.А, Олексеюк ${ }^{2}$ І.Д., Федосов ${ }^{1}$ C.А., Третяк ${ }^{1}$ А.П., Данилюк ${ }^{3}$ I.В., Лебедь ${ }^{4}$ О.О., Кевшин ${ }^{1}$ А.Г., Тищенко ${ }^{2}$ П.В. 
Метою цієї роботи є дослідження впливу $\gamma$-опромінення на спектри ФЛ в монокристалі $\left(\mathrm{Ga}_{54.59} \mathrm{In}_{44.66} \mathrm{Er}_{0.75}\right)_{2} \mathrm{~S}_{300}$.

\section{Синтез сплавів, методика та техніка експерименту}

Ми отримали монокристал $\left(\mathrm{Ga}_{54.59} \mathrm{In}_{44.66} \mathrm{Er}_{0.75}\right)_{2} \mathrm{~S}_{300}$, методика та умови отримання якого підібрані з діаграми стану системи $\mathrm{Ga}_{2} \mathrm{~S}_{3}-\mathrm{In}_{2} \mathrm{~S}_{3}$ та термограми охолодження зразка, по якій визначали температуру переохолодження. Використали розчин-розплавний метод, переохолодження розчину-розплаву становило 70 К. Синтез вихідного сплаву при максимальній температурі 1200 К та ріст кристалу проводили в одному вакуумному кварцовому контейнері 3 дном у вигляді конуса і перетяжкою 3 діаметром отвору 2 мм. Процес росту проходив у вертикальній двозонній печі. Максимальна температура становила $1200 \mathrm{~K}$, градієнт температури на фронті кристалізації складав $20 \mathrm{~K} / \mathrm{cm}$. Після розплавлення шихти, ампулу опускали з максимальною швидкістю. Після кристалізації 10 мм розплаву, по довжині ампули, ріст зупиняли, після чого проводили в зворотному напрямі розплавлення $6.0-8.0$ мм закристалізованого розплаву і протягом 100 годин здійснювали відпал. Далі проводили вирощування монокристалу при швидкості опускання 5 мм/добу. Після завершення процесу обидві печі охолоджували до $820 \mathrm{~K}$ зі швидкістю 50-70 К/добу і відпалювали отриманий монокристал протягом 100 годин. Після цього охолоджували установку в режимі виключеної печі. Отримано монокристал оранжево-жовтого кольору, діаметром 14 мм і довжиною 20 мм. Компонентний склад і структуру вирощеного монокристалу досліджено $з$ допомогою SEM та EDS-аналізу [18].

Дослідження спектрів оптичного поглинання та ФЛ проводилось за стандартною методикою синхродетектування, обладнаною сучасною системою АЦ-перетворювача, монохроматором МДР-206 при кімнатній температурі. Приймання сигналу ФЛ проводилось із тієї ж площини поверхні зразка, що і збудження. Реєстрація сигналу проводилась $\mathrm{Si}$ та $\mathrm{PbS}$ фотоприймачами. Збудження люмінесценції здійснювалось лазером iз максимумом випромінювання 532 нм і потужністю 150 мВт.

Опромінення кристалу проведено джерелом ${ }^{60} \mathrm{Co}$ на повітрі при температурі навколишнього середовища. Середня енергія падаючих $\gamma$-променів була близькою до $1,25 \mathrm{MeB}$. Поглинута доза виміряна 3 використанням пристрою VDEG2-34 SP-1 для виявлення i вимірювання $\gamma$-квантів. Діапазон реєстрації $\gamma$-променів варіюється в межах значень $0,05-3$ $\mathrm{MeB}$. Для дослідження вирізались зразки із центральної частини монокристалу, які опромінювались дозами 420, 1260, 2520, 5040 Гр.

\section{Результати експерименту та обговорення}

Досліджено спектр оптичного поглинання у видимому та близькому інфрачервоному діапазоні монокристалу $\left(\mathrm{Ga}_{54.59} \mathrm{In}_{44.66} \mathrm{Er}_{0.75}\right)_{2} \mathrm{~S}_{300}$ (рис. 1.) Як бачимо на графіку зафіксовано вузькі смуги поглинання із максимумами $0,81,1,27,1,53,1,88,2,34$ еВ. Ці максимуми

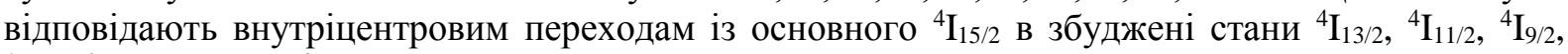
${ }^{4} \mathrm{~F}_{9 / 2},{ }^{2} \mathrm{H}_{11 / 2}$ іонів $\mathrm{Er}^{3+}$ відповідно.

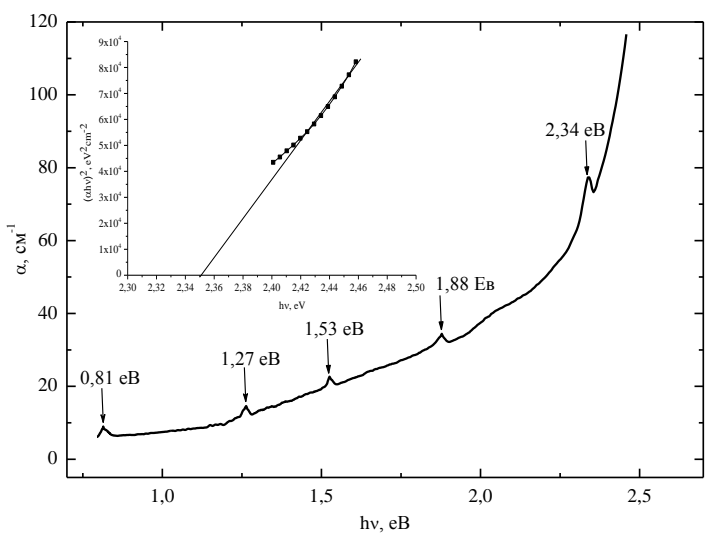

Рис. 1. Спектр оптичного поглинання монокристалу $\left(\mathrm{Ga}_{54.59} \mathrm{In}_{44.66} \mathrm{Er}_{0.75}\right)_{2} \mathrm{~S}_{300}$

На вставці рис. 1 побудовано залежність $(\alpha h v)^{2}=f(h v)$ і на основі відомої формули [19] для прямих переходів визначено ширину забороненої зони кристалу:

(C) Галян ${ }^{1}$ В.В., Іващенко ${ }^{2}$ I.А, Олексеюк ${ }^{2}$ І.Д., Федосов ${ }^{1}$ С.А., Третяк ${ }^{1}$ А.П., Данилюк ${ }^{3}$ І.В., Лебедь ${ }^{4}$ О.О., Кевшин ${ }^{1}$ А.Г., Тищенко ${ }^{2}$ П.В. 


$$
\alpha=A \frac{\left(h v-E_{g}\right)^{\frac{1}{2}}}{h v}
$$

де: $\alpha$ - коефіцієнт поглинання, $E_{g}$ - ширина забороненої зони, $A$ - константа. Визначене значення $E_{g}=2,35 \mathrm{eB}, \epsilon$ дещо меншим, як в роботі I.P. Амірасланова [20], який отримав монокристали $\mathrm{GaInS}_{3}$ методом хімічно-транспортних реакцій. Відмінності пов'язані із різною технологією отримання монокристалів, а також введенням домішки Ербію.

Крім того, ми дослідили спектри ФЛ неопроміненого і опроміненого різними дозами монокристалу ( $\left(\mathrm{Ga}_{54.59} \mathrm{In}_{44.66} \mathrm{Er}_{0.75}\right)_{2} \mathrm{~S}_{300}$ (рис. 2, 3) за кімнатної температури при збудженні лазером із довжиною хвилі 532 нм (2,33 еВ). Як бачимо із рисунків, у видимому і близькому інфрачервоному діапазоні зафіксовано інтенсивні смуги випромінювання із максимумом 1,53 i 0,81 еВ, що відповідає переходам в іонах Ербію ${ }^{4} \mathrm{I}_{9 / 2} \rightarrow{ }^{4} \mathrm{I}_{15 / 2},{ }^{4} \mathrm{I}_{13 / 2} \rightarrow{ }^{4} \mathrm{I}_{15 / 2}$ відповідно. У всіх зразках розташування та форма спектрів випромінювання зберігається i зростає при опроміненні до 2520 Гр. Зауважимо, що явище збільшення інтенсивності фотолюмінесценції та фоточутливості кристалу GaS: $\mathrm{Er}^{3+}$ псля $\gamma$-опромінення спостерігали Р. С. Мадатов, Т. Б. Тагієв та ін. [21]. При подальшому збільшенні дози опромінення до 5040 Гр інтенсивність максимуму при 1,53 еВ не зазнає видимих змін, а при $0,81 \mathrm{eB}$ незначно зменшується.

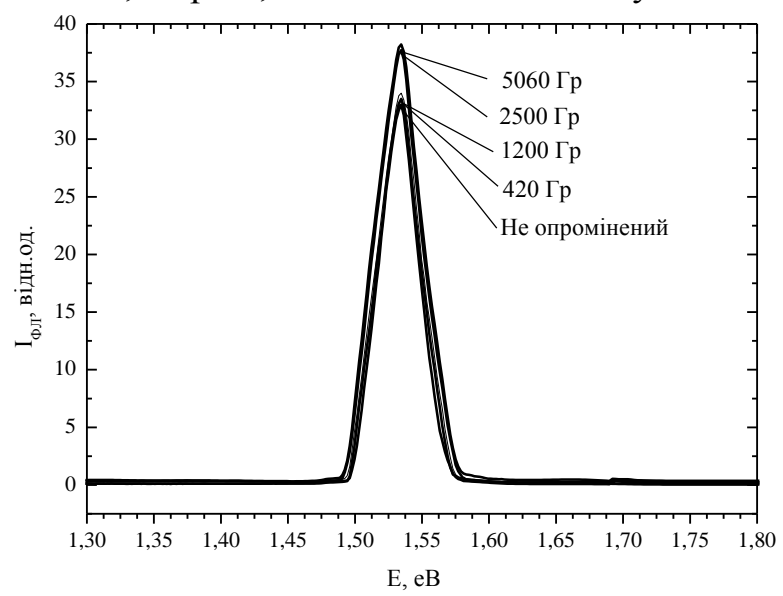

Рис. 2. Видимий діапазон спектрів ФЛ неопроміненого і опроміненого при різних дозах монокристалу (Ga54.59 $\left.\mathrm{In}_{44.66} \mathrm{Er}_{0.75}\right)_{2} \mathrm{~S}_{300}$

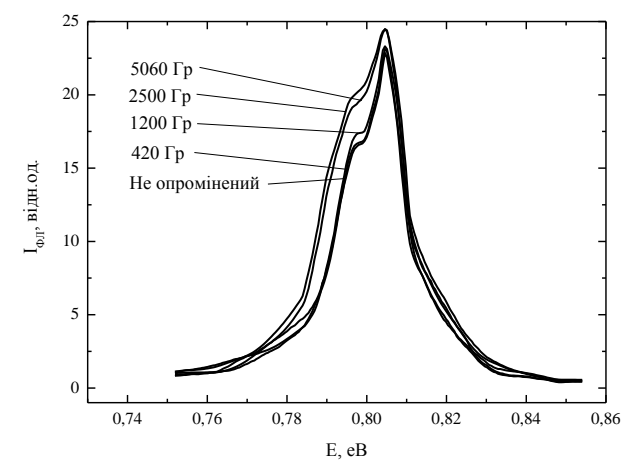

Рис. 3. Інфрачервоний діапазон спектрів ФЛ неопроміненого і опроміненого при різних дозах монокристалу $\left(\mathrm{Ga}_{54.59} \mathrm{In}_{44.66} \mathrm{Er}_{0.75}\right)_{2} \mathrm{~S}_{300}$

Для того щоб зрозуміти механізм випромінювання ми звернулись до діаграми енергетичних переходів в іонах Ербію (рис. 4). Збудження із довжиною хвилі 532 нм (2,33 еВ) переводить іони Ербію із основного в збуджений стан ${ }^{2} \mathrm{H}_{11 / 2}$. Існування інтенсивних смуг ФЛ із максимумами 1,53 і $0,81 \mathrm{eB}$ забезпечується високою концентрацією іонів Ербію в збуджених станах ${ }^{4} \mathrm{I}_{9 / 2}$ i ${ }^{4} \mathrm{I}_{13 / 2}$. Перейти в ці стани іони Ербію можуть двома шляхами: 1) 3 допомогою кросрелаксації CR1; 2) безвипромінювальною релаксацією із стану ${ }^{2} \mathrm{H}_{11 / 2}$ до станів ${ }^{4} \mathrm{I}_{9 / 2}$ i ${ }^{4} \mathrm{I}_{13 / 2}$, через які відбувається ФЛ випромінювання. Безвипромінювально релаксувати у стан ${ }^{4}{ }_{9 / 2}$, іони Ербію не можуть, внаслідок великої енергетичної відстані між станами ${ }^{4} \mathrm{~S}_{3 / 2}-{ }^{4} \mathrm{~F}_{9 / 2}$ та ${ }^{4} \mathrm{~F}_{9 / 2}-{ }^{4} \mathrm{I}_{9 / 2}$.

(C) Галян ${ }^{1}$ В.В., Іващенко ${ }^{2}$ I.А, Олексеюк ${ }^{2}$ І.Д., Федосов ${ }^{1}$ C.А., Третяк ${ }^{1}$ А.П., Данилюк ${ }^{3}$ І.В., Лебедь ${ }^{4}$ О.О., Кевшин ${ }^{1}$ А.Г., Тищенко ${ }^{2}$ П.В. 
За даними роботи [22] енергетична відстань між станами ${ }^{4} \mathrm{~S}_{3 / 2}-{ }^{4} \mathrm{~F}_{9 / 2}$ становить $3071 \mathrm{~cm}^{-1}$ $(0,38 \mathrm{eB})$, а енергія фононів кристалу $\left(\mathrm{Ga}_{54.59} \mathrm{In}_{44.66} \mathrm{Er}_{0.75}\right)_{2} \mathrm{~S}_{300}$, згідно із даними раманівської спектроскопії [18] - $250 \mathrm{~cm}^{-1}(0,031 \mathrm{eB})$. Тому ми вважаємо, що реалізація збуджених станів ${ }^{4} \mathrm{I}_{9 / 2}$ та ${ }^{4} \mathrm{I}_{13 / 2}$ відбувається за участю кросрелаксаційного процесу CR1 (рис. 4).

Кросрелаксація проходить між сусідніми іонами Ербію, які знаходяться в стані ${ }^{2} \mathrm{H}_{11 / 2} \mathrm{i}$ ${ }^{4} \mathrm{I}_{15 / 2}$, внаслідок чого перший іон Ербію переходить в стан ${ }^{4} \mathrm{I}_{9 / 2}$, а другий

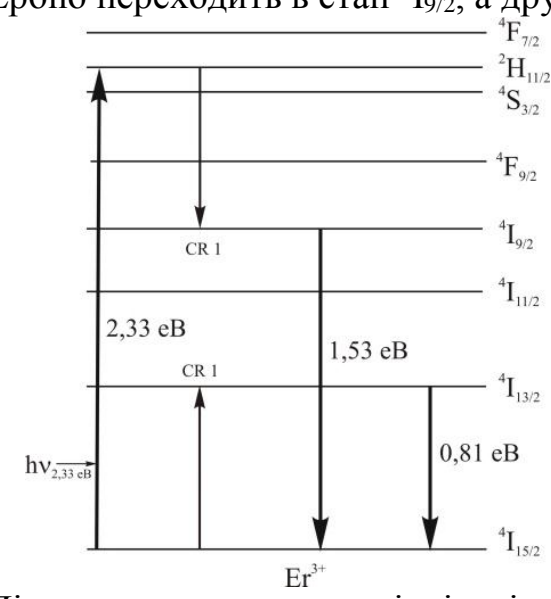

Рис. 4. Діаграма енергетичних рівнів в іонах Ербію

в стан ${ }^{4} \mathrm{I}_{13 / 2}$ згідно із формулою:

$$
{ }^{2} \mathrm{H}_{11 / 2}+{ }^{4} \mathrm{I}_{15 / 2} \rightarrow{ }^{4} \mathrm{I}_{9 / 2}+{ }^{4} \mathrm{I}_{13 / 2}
$$

Як бачимо із діаграми (рис. 4), при такому механізмі велика кількість іонів Ербію переходить в збуджені стани ${ }^{4} \mathrm{I}_{9 / 2},{ }^{4} \mathrm{I}_{13 / 2}$ через які відбувається люмінесцентне випромінювання. Крім того, при високих дозах опромінення $(2500,5060$ Гр) генерується значна концентрація $\gamma$ індукованих дефектів, які впливають на інтенсивність люмінесценції.

На відміну від дослідженого в цій статті монокристалу, в сульфідних склоподібних сплавах [5, 6] спостерігається велика кількість смуг випромінювання, але 3 меншою інтенсивністю. Це пов'язано з тим, що іони Ербію в стеклах можуть займати декілька позицій і 3 кожної можемо фіксувати ФЛ випромінювання. Також в стеклах під впливом $\gamma$-опромінення [23] змінюється механізм люмінесцентного випромінювання. В монокристалі $\left(\mathrm{Ga}_{54.59} \mathrm{In}_{44.66} \mathrm{Er}_{0.75}\right)_{2} \mathrm{~S}_{300}$ значних змін у спектрах люмінесценції під впливом $\gamma$-опромінення не зафіксовано, що визначає його перевагу в радіаційній стійкості для можливого застосування в оптоелектронній техніці.

\section{Висновки}

Досліджено спектри оптичного поглинання монокристалу $\left.\mathrm{Ga}_{54.59} \operatorname{In}_{44.66} \mathrm{Er}_{0.75}\right)_{2} \mathrm{~S}_{300}$ i визначено ширину забороненої зони, яка становить $2,35 \mathrm{eB}$. Зафіксовану ФЛ в інтервалі $1,48-$ 1,61 i 0,75 - 0,86 еВ пов'язуємо 3 внутріцентровими переходами в іонах Ербію. Після опромінення зразків розташування та форма максимумів ФЛ не змінилась, що свідчить про радіаційну стійкість монокристалу $\left(\mathrm{Ga}_{54.59} \mathrm{In}_{44.66} \mathrm{Er}_{0.75}\right)_{2} \mathrm{~S}_{300}$. Вважаємо, що збільшення інтенсивності ФЛ при великих дозах опромінення пов'язано із виникненням значної кількості $\gamma$-індуковних дефектів.

\section{Інформаційні джерела}

1. Band structure, electronic and optical features of $\mathrm{Tl}_{4} \mathrm{SnX}_{3}(\mathrm{X}=\mathrm{S}, \mathrm{Te})$ ternary compounds for optoelectronic applications / M. Piasecki, M.G. Brik, I.E. Barchiy, K. Ozga, I.V. Kityk, A.M. El-Naggar, A.A. Albassam, T.A. Malakhovskaya, G. Lakshminarayana. // Journal of Alloys and Compounds. - 2017. - Vol. 710. - P. 600-607.

2. Concentration dependence of the optical properties of glassy alloys in the $\mathrm{HgS}-\mathrm{Ga}_{2} \mathrm{~S}_{3}-$ $\mathrm{GeS}_{2}$ system / A.H. Kevshyn, V.V. Halyan, H.Ye. Davydyuk, O.V. Parasyuk, I.I. Mazurets // Glass Physics and Chemistry. - 2010. - Vol. 36. - P. 27-32.

3. Huge operation by energy gap of novel narrow band gap $\mathrm{Tl}_{1-\mathrm{x}} \mathrm{In}_{1-\mathrm{x}} \mathrm{B}_{\mathrm{x}} \mathrm{Se}_{2}(\mathrm{~B}=\mathrm{Si}, \mathrm{Ge})$ : DFT, x-ray emission and photoconductivity studies / M. Piasecki, G.L. Myronchuk, O.V. Zamurueva, O.Y. Khyzhun, O.V. Parasyuk, A.O. Fedorchuk, A. Albassam, A.M. El-Naggar, I.V. Kityk // Materials Research Express. - 2016. - Vol. 3. - P. 025902.

(C) Галян ${ }^{1}$ В.В., Іващенко ${ }^{2}$ I.А, Олексеюк ${ }^{2}$ І.Д., Федосов ${ }^{1}$ С.А., Третяк ${ }^{1}$ А.П., Данилюк ${ }^{3}$ І.В., Лебедь ${ }^{4}$ О.О., Кевшин ${ }^{1}$ А.Г., Тищенко ${ }^{2}$ П.В. 
4. Phase equilibria in the quasi-ternary system $\mathrm{Ag}_{2} \mathrm{Se}-\mathrm{Ga}_{2} \mathrm{Se}_{3}-\mathrm{In}_{2} \mathrm{Se}_{3}$ and physical properties of $\left(\mathrm{Ga}_{0.6} \mathrm{In}_{0.4}\right)_{2} \mathrm{Se}_{3},\left(\mathrm{Ga}_{0.594} \mathrm{In}_{0.396} \mathrm{Er}_{0.01}\right)_{2} \mathrm{Se}_{3}$ single crystals / I.A. Ivashchenko, I.V. Danyliuk, I.D. Olekseyuk, V.V. Halyan // Journal of Solid State Chemistry. - 2014. - Vol. 210. - P. 102-110.

5. Role of structural ordering on optical properties of the glasses $A_{0,05} \mathrm{Ga}_{0,05} \mathrm{Ge}_{0,95} \mathrm{~S}_{2}-$ $\mathrm{Er}_{2} \mathrm{~S}_{3}$ / V.V. Halyan, V.V. Strelchuk, V.O. Yukhymchuk, A.H. Kevshyn, G.Ye. Davydyuk, M.V. Shevchuk, S.V. Voronyu // Physica B. - 2013. - Vol. 411. - P. 35-39.

6. Effect of temperature on the structure and luminescence properties of $\mathrm{Ag}_{0.05} \mathrm{Ga}_{0.05} \mathrm{Ge}_{0.95} \mathrm{~S}_{2}-\mathrm{Er}_{2} \mathrm{~S}_{3}$ glasses / V.V. Halyan, I.V. Kityk, A.H. Kevshyn, I.A. Ivashchenko, G. Lakshminarayana, M.V. Shevchuk, A. Fedorchuk, M. Piasecki // Journal of Luminescence. - 2017. - 181. - P. 315-320.

7. Raman and photoluminescence characterization of diamond films for radiation detectors / Iu. Nasieka, V. Strelchuk, M. Boyko, V. Voevodin, A. Vierovkin, A. Rybka, V. Kutniy, S. Dudnik, V. Gritsina, O. Opalev, V. Strel'nitskij // Sensors and Actuators, A: Physical. - 2015. Vol. 223. - P. 18-23.

8. Influence of electron beam irradiation on nonlinear optical properties of $\mathrm{Al}$ doped $\mathrm{ZnO}$ thin films for optoelectronic device applications in the cw laser regime / Albin Antony, S. Pramodini, P. Poornesh, I.V. Kityk, A.O. Fedorchuk, Ganesh Sanjeev // Optical Materials. - 2016. - Vol. 62. - P. $64-71$.

9. P.A. Rodnyi. Progress in fast scintillators // Radiation Measurements. - 2001. - Vol. 33, No 5. - P. 605-614.

10. Study of VUV emission and $\gamma$-ray responses of Nd:BaF2 scintillaotor / Takayuki Yanagida, Noriaki Kawaguchi, Yuui Yokota, Sumito Ishidu, Kei Kamada. // Radiation Measurements. - 2010. - Vol. 45, No 3-6. - P. 422-425.

11. Takayuki Yanagida. Ionizing radiation induced emission: Scintillation and storagetype luminescence // Journal of Luminescence. - 2016. - Vol. 169, Part B. - P. 544-548.

12. Gamma radiation induced loss in erbium doped optical fibers / B. Tortech, M. Van Uffelen, A. Gusarov, Y. Ouerdane, A. Boukenter, J.-P. Meunier, F. Berghmans, H. Thienpont // J. Non-Cryst. Solids. - 2007. - Vol. 353, No 5-7. - P. 477-480.

13. Enhanced radiation resistance of near-infrared photoluminescence emission induced by Er/Si nanoclustering / C. Wang, D. Barba, S. Slim, Y.Q. Wang, F. Rosei // Materials \& Design. 2017. - Vol. 126. - P. 57-63.

14. Scintillation properties of Er-doped $\mathrm{Y}_{3} \mathrm{Al}_{5} \mathrm{O}_{12}$ single crystals / Akihiro Yamaji, Hiraku Ogino, Yutaka Fujimoto, Akira Suzuki, Akira Yoshikawa // Radiation Measurements. - 2013. - Vol. 56. - P. 116-119.

15. Crystal growth and scintillation properties of Er-doped $\mathrm{Lu}_{3} \mathrm{~A}_{15} \mathrm{O}_{12}$ single crystals / Makoto Sugiyama, Yutaka Fujimoto, Takayuki Yanagida, Daisuke Totsuka, Shunsuke Kurosawa, Yoshisuke Futami, Yuui Yokota, Valery Chani, Akira Yoshikawa // Accelerators, Spectrometers, Detectors and Associated Equipment. - 2012. - Vol. 664. - P. 127-131.

16. Phase equilibria in the quasiternary system $\mathrm{Ag}_{2} \mathrm{~S}-\mathrm{Ga}_{2} \mathrm{Se}_{3}-\mathrm{In}_{2} \mathrm{Se}_{3}$ and optical properties of $\left(\mathrm{Ga}_{55} \mathrm{In}_{45}\right)_{2} \mathrm{~S}_{300}, \quad\left(\mathrm{Ga}_{54.59} \mathrm{In}_{44.66} \mathrm{Er}_{0.75}\right)_{2} \mathrm{~S}_{300}$ single crystals / I.A. Ivashchenko, I.V. Danyliuk, I.D. Olekseyuk, V.Z. Pankevych, V.V. Halyan // Journal of Solid State Chemistry. - 2015. - Vol. 227. - P.255-264.

17. Electronic structure of $\left(\mathrm{Ga}_{55} \mathrm{In}_{45}\right)_{2} \mathrm{~S}_{300}$ and $\left(\mathrm{Ga}_{54.59} \mathrm{In}_{44.66} \mathrm{Er}_{0.75}\right)_{2} \mathrm{~S}_{300}$ single crystals / O.Y. Khyzhun, V.V. Halyan, I.V. Danyliuk, I.A. Ivashchenko // Journal of Materials Science: Materials in Electronics. - 2016. - Vol. 27. - P. 3258 - 3264.

18. Laser stimulated piezo-optics of $\gamma$-irradiated $\left(\mathrm{Ga}_{55} \mathrm{In}_{45}\right)_{2} \mathrm{~S}_{300}$ and $\left(\mathrm{Ga}_{54.59} \mathrm{In}_{44.66} \mathrm{Er}_{0.75}\right)_{2} \mathrm{~S}_{300}$ single crystals / I.V. Kityk, V.O. Yukhymchuk, A. Fedorchuk, V.V. Halyan, I.A. Ivashchenko, I.D. Oleksieyuk, M.A. Skoryk, G. Lakshminarayana, A.M. El-Naggar, A.A. Albassam, O.O. Lebed, M. Piasecki // Journal of Alloys and Compounds. - 2017. - Vol. 722. P. 265-271.

19. Ж. Панков. Оптические процессы в полупроводниках. - Москва: Мир, 1973. $456 \mathrm{c}$.

20. Выращивание монокристаллов, структура и фотоэлектрические свойства новых полиморфных модификаций $\mathrm{GaInS}_{3}$ / И.Р. Амирасланов,Т.Х. Азизов, Г.Г. Гусейнов, А.С. Кулиев, Г.М. Нифтиев // Неорг. Матер. - 1988. - Vol. 24, №5. - 723-726.

(C) Галян ${ }^{1}$ В.В., Іващенко ${ }^{2}$ I.А, Олексеюк ${ }^{2}$ І.Д., Федосов ${ }^{1}$ C.А., Третяк ${ }^{1}$ А.П., Данилюк ${ }^{3}$ I.В., Лебедь ${ }^{4}$ О.О., Кевшин ${ }^{1}$ А.Г., Тищенко ${ }^{2}$ П.В. 
21. Optical and photoelectric properties of gamma-irradiated $\mathrm{GaS}: \mathrm{Er}^{3+}$ layered crystals /A. R. S. Madatov, T. B. Tagiev, S.A. Abushev, Sh.P. Shekili, A.R. Mobili // Inorganic Materials. -2008. - Vol. 44, No 4. - 333-336.

22. $\mathrm{Er}^{3+}$ to glass matrix energy transfer in $\mathrm{Ga}-\mathrm{Ge}-\mathrm{S}: \mathrm{Er}^{3+}$ system / T.Yu. Ivanova, A.A. Man'shina, A.V. Kurochkin, Yu.S. Tver'yanovich, V.B. Smirnov // J. Non-Cryst. Solids. - 2002. - Vol. 298. - P. 7-14.

23. EPR of $\gamma$-induced defects and their effects on the photoluminescence in the glasses of the $\mathrm{Ag}_{0.05} \mathrm{Ga}_{0.05} \mathrm{Ge}_{0.95} \mathrm{~S}_{2}-\mathrm{Er}_{2} \mathrm{~S}_{3}$ system / V.V. Halyan, A.A. Konchits, B.D. Shanina, S.V. Krasnovyd, O.O. Lebed, A.H. Kevshyn, M.V. Shevchuk, A.V. Bodnaruk, V.O. Yukhymchuk // Radiation Physics and Chemistry. - 2015. - Vol. 115. - P. 189-195.

Галян В.В., Иващенко И.А., Олексеюк И.Д., Федосов С.А., Третяк А.П., Данилюк І.В., Лебедь О.О., Кевшин А.Г., Тищенко П.В.

Восточноевропейский национальный университет имени Леси Украинки, Луцк

Национальный университет водного хозяйства и природопользования, Ровно

\title{
МЕХАНИЗМ ФОТОЛЮМИНЕСЦЕНЦИИ МОНОКРИСТАЛЛА \\ $\left(\mathbf{G a}_{54.59} \mathbf{I n}_{44.66} \mathbf{E r}_{0.75}\right)_{2} \mathbf{S}_{300}$
}

Монокристалл $\left(\mathrm{Ga}_{54.59} \mathrm{In}_{44.66} \mathrm{Er}_{0.75}\right)_{2} \mathrm{~S}_{300}$ выращенный методом раствора-расплава и облученный $\gamma$-лучами дозой $420,1260,2520,5040$ Гр с помощью источника ${ }^{60} \mathrm{Co}$. Зафиксировано интенсивное люминесцентное излучение в интервалах $1,48-1,61$ и $0,75-$ 0,86 эВ при возбуждении лазером с длиной волны 532 нм. Построена диаграмма энергетических уровней для ионов эрбия и установлен механизм излучения, в котором важную роль играет процесс кроссрелаксации. При высоких дозах облучения (2520, 5040 Гр) происходит увеличение интенсивности люминесцентного излучения, которое связывается с ростом концентрации $\gamma$-индуцированных дефектов кристалла.

Ключевые слова: фотолюминесценция, кроссрелаксация, спектр поглощения.

\author{
Halyan V.V., Ivashchenko I.A., Olekseuk I.D., Fedosov S.A., Tretyak A.P., Danyliuk I.V., \\ Lebed O.O., Kevshyn A.H., Tishchenko P.V. \\ Lesya Ukrainka Eastern European National University, Lutsk \\ National University for Water Economy and Nature Management, Rivne
}

\section{MECHANISM OF PHOTOLUMINESCENCE IN (Ga54.59In 44.66 $\left._{\text {E }} \mathbf{r}_{0.75}\right)_{2} \mathbf{S}_{300}$ SINGLE CRYSTAL}

Using solution-melt method $\left(\mathrm{Ga}_{54.59} \mathrm{In}_{44.66} \mathrm{Er}_{0.75}\right)_{2} \mathrm{~S}_{300}$ single crystal was grown. The single crystal specimens were irradiated of the $\gamma$-radiation with the doses of 420, 1260, 2520, $5040 \mathrm{Gr}$ with the help of a ${ }^{60} \mathrm{Co}$ source. An intense luminescent radiation was recorded in the range of $1.48-1.61$ and $0.75-0.86 \mathrm{eV}$ under laser excitation with $532 \mathrm{~nm}$ wavelength. A diagram of energy levels for erbium ion was constructed and the mechanism of radiation was established, in which the crossrelaxation process plays an important role. At high doses of irradiation $(2520,5040 \mathrm{Gr})$ the intensity of the luminescent radiation increases, that we associate with increase in the concentration of $\gamma$-induced defects in the crystal.

Keywords: photoluminescence, cross-relaxation, absorption spectrum. 